\title{
Application of fitting parameters in best fit equation
}

\author{
Zhai Qian ${ }^{1}$, Harianto Rahardjo ${ }^{1, a}$ \\ ${ }^{1}$ School of Civil and Environmental Engineering, Nanyang Technological University, 50 Nanyang Avenue, Singapore
}

\begin{abstract}
Soil-water characteristic curve (SWCC) contains key information for the application of unsaturated soil mechanics principles to engineering practice. SWCC variables such as air-entry value, residual suction and residual saturation are commonly referred to for estimation of other unsaturated soil properties. Though there are clear definitions for these SWCC variables, it is difficult to measure them directly in laboratory and these SWCC variables are commonly estimated from SWCC. Hydraulic conductivity of unsaturated soil is the major property that controls water flow in soil. The laboratory measurement of hydraulic conductivity is time consuming and costly. Therefore, hydraulic conductivity is also commonly estimated from SWCC. Normally, SWCC is represented by a best fit equation which is typically governed by few fitting parameters. These fitting parameters can be obtained from a best fit procedure and are proven to be dependent on each other. Fredlund and Xing's (1994) equation is one of the popular equations commonly used by researchers and there are only three fitting parameters such as "a", " $\mathrm{n}$ ", " $\mathrm{m}$ " in this equation. Correlation equations between SWCC variables, hydraulic conductivity and the fitting parameters such as "a", "n" and "m" are presented in this paper. In addition, the variability in the determined SWCC variables and hydraulic conductivity due to the variation in these fitting parameters is also discussed in this paper.
\end{abstract}

\section{Introduction}

SWCC is normally determined from several experimental data and a best fit equation is adopted to provide a continuous model. The best fit equation is normally governed by a few fitting parameters and these fitting parameters are typically determined using a curve fitting technique. As the fitting parameters are determined from a regression procedure, these fitting parameters are mathematical solutions rather than physical soil properties.

SWCC variables such as air-entry value, residual suction and residual saturation are commonly referred to for the description of unsaturated soil properties (e.g., shear strength such as Vanapalli et al.'s 1996 equation, constitutive model such as Sheng et al. 2008). These SWCC variables are conventionally determined using the graphical method with subjective interpretation. In addition, permeability function or hydraulic conductivity of unsaturated soil is the essential information required for seepage analysis. As the experimental measurement of hydraulic conductivity of unsaturated soil is tedious and costly, the unsaturated hydraulic conductivity is commonly estimated from SWCC. The mathematical equations to correlate the SWCC variables, hydraulic conductivity and the fitting parameters in Fredlund and Xing's (1994) equation are derived and illustrated in this paper. The variability in the determined SWCC variables and hydraulic conductivity due to variation in these fitting parameters is also discussed in this paper.

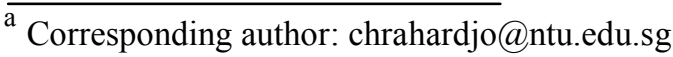

\section{Literature review}

Various researchers developed different equations to describe soil-water characteristic curve (SWCC) (Brooks and Corey, 1964; Gardner, 1958; Farrel and Larson, 1972; van Genuchten, 1980; Williams et al., 1983; Fredlund and Xing, 1994; Kosugi, 1994 and Satyanaga et al., 2013). Studies by Leong and Rahardjo (1997a) and Zapata (1999) concluded that Fredlund and Xing's (1994) equation performed best among different equations to best fit SWCC. Leong and Rahardjo (1997a) suggested that Fredlund and Xing (1994) equation can be used for a wide range of soil over the entire range of matric suction. Zhai and Rahardjo (2012a, 2013a) derived equations for determination of SWCC variables from fitting parameters of Fredlund and Xing's (1994) equation. Zhai and Rahardjo (2015) derived equations for estimation of hydraulic conductivity from SWCC using capillary model. In addition, fitting parameters are commonly obtained with the accompanying residual error after the regression procedure. Fitting parameters are then used while the residual error is always discarded. In fact, the residual error is helpful for the estimation of variance of fitting parameters and confidence limits of the best fitted SWCC. Zhai and Rahardjo (2013b) proposed equations for the estimation of variance of these fitting parameters from the residual error using the first-order error method. Confidence limits of SWCC were also proposed by Zhai and Rahardjo (2013b) using variance of fitting parameters. Consequently, the variability in SWCC variables and hydraulic conductivity can also be 
estimated from variance of the fitting parameters and is discussed in this paper.

By introducing the concept of pore-size distribution function, Fredlund and Xing (1994) proposed the best fit equation as follows:

$$
\theta=C(\psi) \frac{\theta_{s}}{\left\{\ln \left[e+\left(\frac{\psi}{a}\right)^{n}\right]\right\}^{m}}=\left[1-\frac{\ln \left(1+\frac{\psi}{C_{r}}\right)}{\ln \left(1+\frac{10^{6}}{C_{r}}\right)}\right] \frac{\theta_{s}}{\left\{\ln \left[e+\left(\frac{\psi}{a}\right)^{n}\right]\right\}^{m}}
$$

where,

a, n, m: fitting parameters;

$\mathrm{C}_{\mathrm{r}}$ : parameter related to residual suction that can be selected as $\mathrm{C}_{\mathrm{r}}=1500 \mathrm{kPa}$ for most cases (Fredlund and Xing 1994, Zhai and Rahardjo 2012a, 2012b).

$\theta \mathrm{s}$ : saturated volumetric water content.

Zhai and Rahardjo (2012a) presented the graphical method for the estimation of SWCC variables from SWCC as illustrated in Fig. 1.

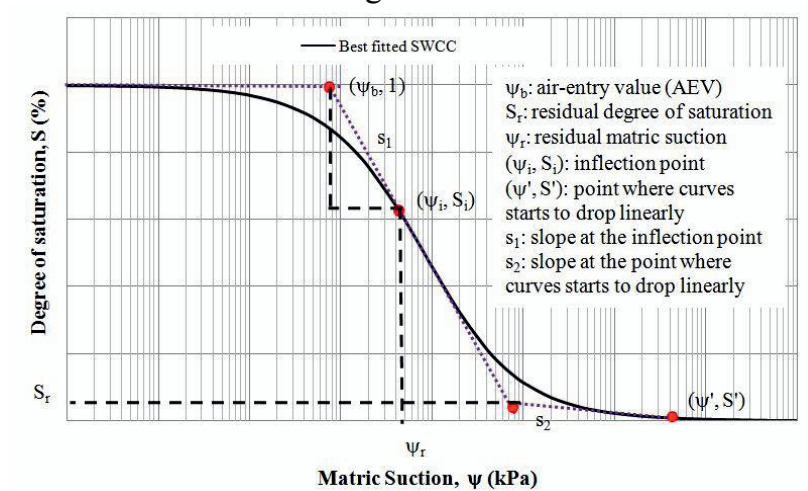

Figure. 1 Definitions of SWCC variables after Zhai and Rahardjo (2012a)

Zhai and Rahardjo (2015) presented that SWCC in the form of degree of saturation could be considered as analogous to the pore-size distribution function or poresuction distribution function. The capillary model was illustrated by dividing SWCC into different intervals $(\Delta \psi)$ to represent capillary tubes with different radii as shown in Fig. 2. Zhai and Rahardjo (2015) derived an equation for the estimation of hydraulic conductivity from SWCC using the theory of random connections and Poiseuille's law

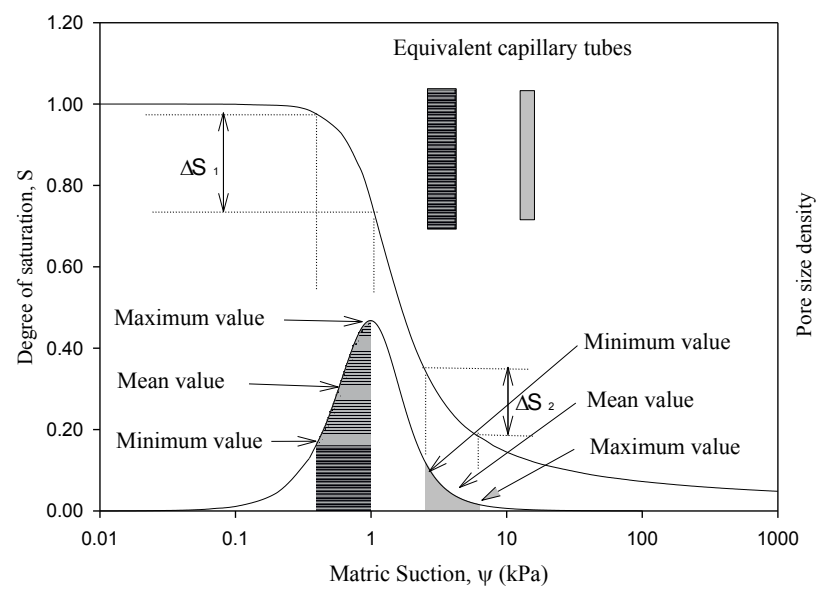

Figure. 2 Illustration of equivalent capillary tubes associated with the pore-suction distribution function.

\section{Theory}

The equations for computation of SWCC variables, unsaturated hydraulic conductivity from the SWCC fitting parameters are derived in this section.

\subsection{Determination of the inflection point.}

SWCC is commonly plotted in a log-arithmetic scale rather than an arithmetic scale. The slope of the plot in the log-arithmetic scale is different from the slope of the plot in the arithmetic scale. The relationship between the slopes of the plots in two different scales can be obtained from Equation (2).

$s=s^{\prime} \ln (10) \psi$

where,

$\mathrm{s}=$ slope plotted in log-arithmetic scale,

$\mathrm{s}$ '= slope plotted in arithmetic scale

$\psi=$ matric suction.

The inflection point is a point on a curve at which the curve changes from being concave (concave downward) to convex (concave upward), or vice versa. If $x$ is an inflection point for the function $f(x)$ then the second derivative, $\mathrm{f}^{\prime \prime}(\mathrm{x})$, should be equal to zero if the inflection point exists. Therefore, the inflection point on the SWCC can be obtained by solving the following differential equation as illustrated in Equation (3).

$$
\frac{d^{2} S}{d(\log (\psi))^{2}}=\ln (10) \psi\left[\frac{d^{2} S}{d \psi^{2}} \ln (10) \psi+\frac{d S}{d \psi} \ln (10)\right]=0
$$

\subsection{Determination of air-entry value, residual suction and residual saturation.}

The slope of SWCC using Fredlund and Xing's (1994) equation can be obtained from Equation (4) as follows:

$$
s=\left\{\begin{array}{c}
\ln \left(1+\frac{10^{6}}{C_{r}}\right)\left(1+\frac{\psi}{C_{r}}\right) C_{r}\left\{\ln \left[e+\left(\frac{\psi}{a}\right)^{n}\right]\right\}^{m} \\
+\frac{m n\left(\frac{\psi}{a}\right)^{n-1}\left[1-\frac{\ln \left(1+\frac{\psi}{C_{r}}\right)}{\ln \left(1+\frac{10^{6}}{C_{r}}\right)}\right]}{a\left[e+\left(\frac{\psi}{a}\right)^{n}\right]\left\{\ln \left[e+\left(\frac{\psi}{a}\right)^{n}\right]\right\}^{m+1}}
\end{array}\right\} \ln (10) \psi
$$

Zhai and Rahardjo (2012a) presented that air-entry value $(\mathrm{AEV})$, residual suction $\left(\psi_{\mathrm{r}}\right)$ and residual saturation $\left(\mathrm{S}_{\mathrm{r}}\right)$ could be obtained from Equations (5) to (7) as follows:

$$
A E V=\psi_{i} 0.1^{\frac{1-S_{i}}{s_{1}}}
$$




$$
\begin{aligned}
& \psi_{r}=10 \frac{S_{i}-S^{\prime}+s_{1} \log \left(\psi_{i}\right)-s_{2} \log \left(\psi^{\prime}\right)}{s_{1}-S_{2}} \\
& S_{r}=S_{i}-s_{1} \log \left(\psi_{r} / \psi_{i}\right)
\end{aligned}
$$

where:

$\mathrm{AEV}=$ air-entry value

$\psi_{\mathrm{i}}=$ suction corresponding to the inflect ion point

$\mathrm{S}_{\mathrm{i}}=$ degree of saturation corresponding to the inflection point

$\mathrm{s}_{1}=$ slope at the inflection point.

Estimation of hydraulic conductivity

Zhai and Rahardjo (2015) derived the equation for the prediction of permeability function using capillary model and Poiseuille's law. By substituting fitting parameters "a", " $\mathrm{n}$ " and "m" into equation (8) as proposed by Zhai and Rahardjo (2015), hydraulic conductivity can be computed.

$$
\begin{aligned}
& k\left(\psi_{m+i}\right)=k\left(\psi_{m}\right) \frac{n_{m+i}{ }^{2}}{n_{m}{ }^{2}} \\
& \left\{\begin{array}{c}
\left(S\left(\psi_{m+i}\right)-S\left(\psi_{m+i+1}\right)\right)^{2} r_{m+i}^{2}+ \\
\sum_{j=m+i+1}^{N}\left[\left(S\left(\psi_{m+i}\right)-S\left(\psi_{j}\right)\right)^{2}-\left(S\left(\psi_{m+i}\right)-S\left(\psi_{j-1}\right)\right)^{2}\right] r_{j}^{2}
\end{array}\right\} \\
& \left\{\begin{array}{c}
\left(S\left(\psi_{m}\right)-S\left(\psi_{m+1}\right)\right)^{2} r_{m}^{2}+ \\
\sum_{i=m+1}^{N}\left[\left(S\left(\psi_{m}\right)-S\left(\psi_{i}\right)\right)^{2}-\left(S\left(\psi_{m}\right)-S\left(\psi_{i-1}\right)\right)^{2}\right] r_{i}^{2}
\end{array}\right]^{-1}
\end{aligned}
$$

where,

$\mathrm{k}\left(\psi_{\mathrm{m}+\mathrm{i}}\right), \mathrm{k}\left(\psi_{\mathrm{m}}\right)=$ hydraulic conductivity corresponding to suction $\psi_{\mathrm{m}+\mathrm{i}}$ and $\psi_{\mathrm{m}}$, respectively;

$\psi_{\mathrm{m}+\mathrm{i}}, \psi_{\mathrm{m}}=$ suction in the soil, $\psi_{\mathrm{m}+\mathrm{i}},>\psi_{\mathrm{m}}$.

$\mathrm{n}_{\mathrm{m}+\mathrm{i}}, \mathrm{n}_{\mathrm{m}}=$ porosity corresponding suction of $\psi_{\mathrm{m}+\mathrm{i}}$ and $\psi_{\mathrm{m}}$, respectively;

$r_{m+i}, r_{m}=$ equivalent pore radius of pores corresponding to suction of $\psi_{\mathrm{m}+\mathrm{i}}$ and $\psi_{\mathrm{m}}$ using Kelvin's capillary law, respectively;

$\mathrm{S}\left(\psi_{\mathrm{m}+\mathrm{i}}\right), \mathrm{S}\left(\psi_{\mathrm{m}}\right)=$ degree of saturation in the soil corresponding to suction of $\psi_{\mathrm{m}+\mathrm{i}}$ and $\psi_{\mathrm{m}}$, respectively;

Estimation of variability in determined SWCC variables and hydraulic conductivity

By adopting the first-order error method, Zhai and Rahardjo (2013b) proposed equations (9) and (10) to estimate the confidence limits of SWCC as follows:

$$
\begin{aligned}
& \text { when } 0<\psi<\mathrm{a}_{\text {max }}, \\
& \theta_{\text {upper }}=C(\psi) \frac{\theta_{s}}{\left\{\ln \left[e+\left(\frac{\psi}{a_{\text {max }}}\right)^{n_{\max }}\right]\right\}^{m_{\min }}}
\end{aligned}
$$

when $\psi>\mathrm{a}_{\text {max }}$,

$$
\theta_{\text {upper }}=C(\psi) \frac{\theta_{s}}{\left\{\ln \left[e+\left(\frac{\psi}{a_{\max }}\right)^{n_{\min }}\right]\right\}^{m_{\min }}}
$$

when $0<\psi<\mathrm{a}_{\min }$,

$$
\theta_{\text {lower }}=C(\psi) \frac{\theta_{s}}{\left\{\ln \left[e+\left(\frac{\psi}{a_{\text {min }}}\right)^{n_{\min }}\right]\right\}^{m_{\max }}}
$$

when $\psi>\mathrm{a}_{\max }$,

$$
\theta_{\text {lower }}=C(\psi) \frac{\theta_{s}}{\left\{\ln \left[e+\left(\frac{\psi}{a_{\text {min }}}\right)^{n_{\max }}\right]\right\}^{m_{\min }}}
$$

where,

$$
\begin{aligned}
& a_{\text {max }}=a+t_{\alpha / 2} \sqrt{\operatorname{Var}(a)} a_{\text {min }}=a-t_{\alpha / 2} \sqrt{\operatorname{Var}(a)} \\
& n_{\text {max }}=n+t_{\alpha / 2} \sqrt{\operatorname{Var}(n)} n_{\text {min }}=n-t_{\alpha / 2} \sqrt{\operatorname{Var}(n)} \\
& m_{\text {max }}=m+t_{\alpha / 2} \sqrt{\operatorname{Var}(m)} \\
& m_{\text {min }}=m-t_{\alpha / 2} \sqrt{\operatorname{Var}(m)} \quad \text { a, } \mathrm{n} \text { and } \mathrm{m} \text { are fitting }
\end{aligned}
$$

parameters.

The variability in SWCC variables and hydraulic conductivity can be estimated from the confidence limits of SWCC (using the proposed equations with $\mathrm{a}_{\max }, \mathrm{a}_{\min }$, $\mathrm{n}_{\max }, \mathrm{n}_{\min }, \mathrm{m}_{\max }, \mathrm{m}_{\min }$ instead of $\mathrm{a}, \mathrm{n}$ and $\mathrm{m}$ ).

\section{Applications and Discussions}

To evaluate the correlations among SWCC variables, unsaturated hydraulic conductivity and the fitting parameters of SWCC, soils with available experimental data of both SWCC and permeability function are selected in this paper. Four types of soil such as Volcanic Sand, Glass Beads, Fine sand and Touch Silt Loam from Brooks and Corey (1964) are selected for this study. The experimental data of SWCC and relative hydraulic conductivity for these four types soil are illustrated in Figures. 3 and 4. 


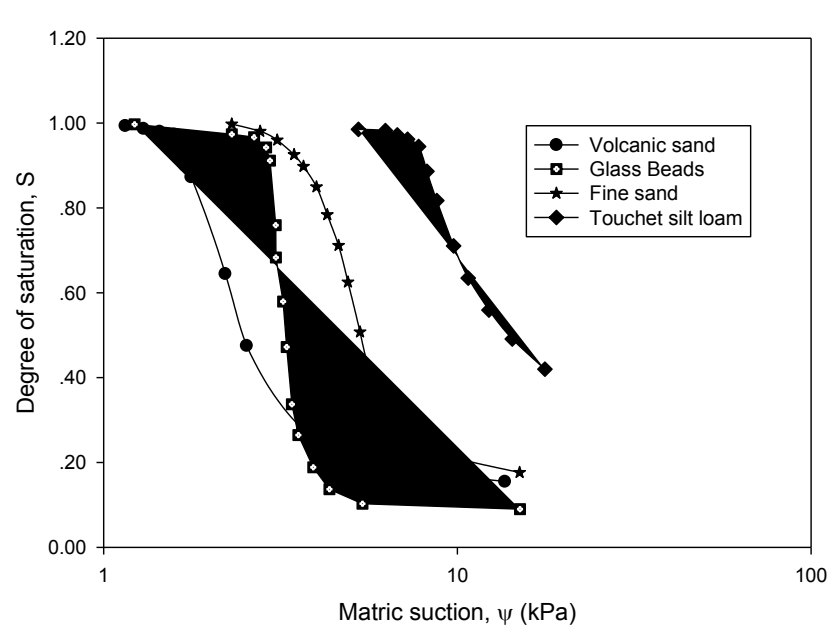

Figure. 3 SWCC of four types of soil from Brooks and Corey (1964)

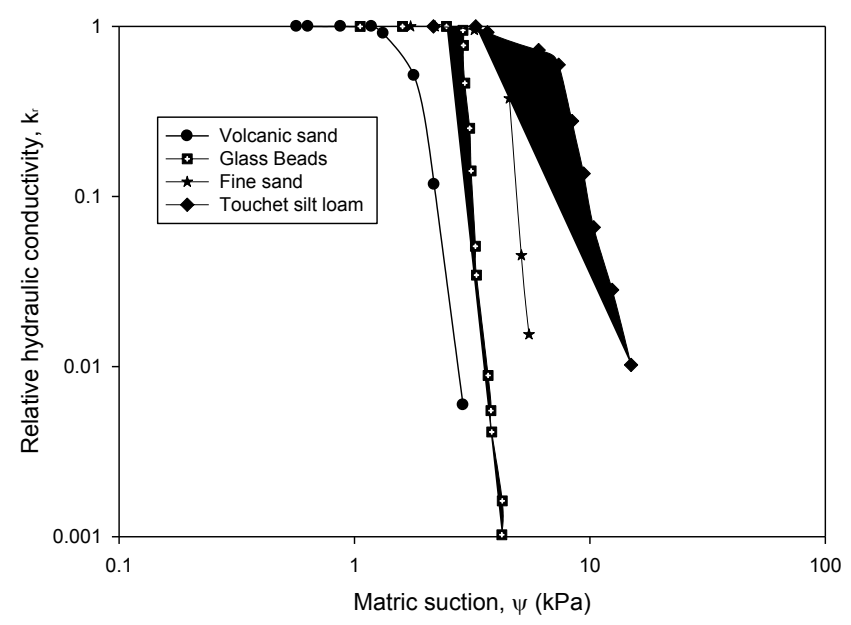

Figure. 4 SWCC of four types of soil from Brooks and Corey (1964)

The fitting parameters for the four types of soil, using the input value $\mathrm{C}_{\mathrm{r}}=1500 \mathrm{kPa}$, obtained from the best fit procedure are summarized in Table 1. The SWCC variables computed from the fitting parameters using the equations proposed in this paper are illustrated in Table 2. The comparison of the estimated relative hydraulic conductivity and the experimental data for the four types of soil are illustrated in Figure. 5.

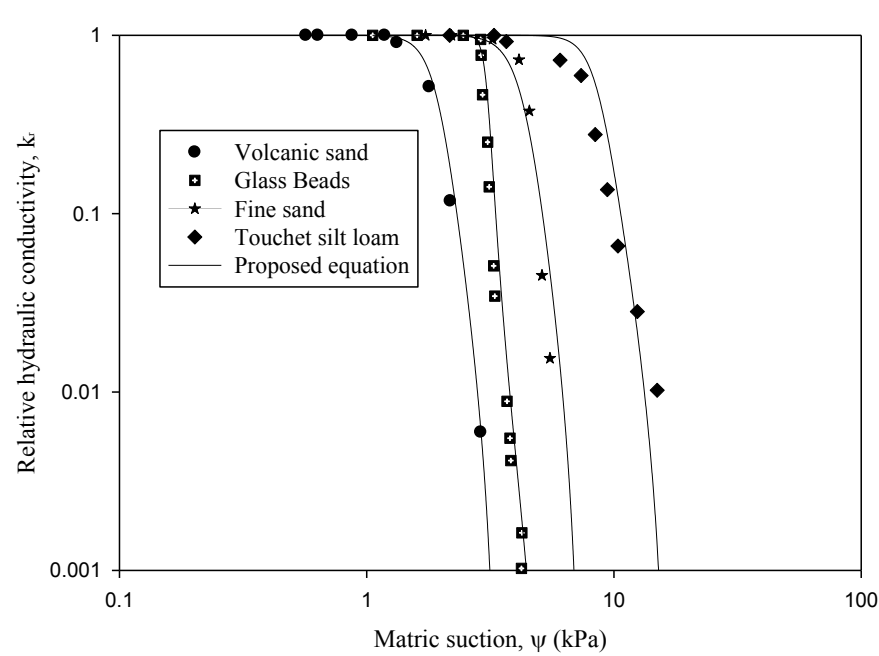

Figure. 5 Comparison of estimated hydraulic conductivity and experimental data for four types of soil

Table 1: Fitting parameters for these four types of soil

\begin{tabular}{|c|c|c|c|c|c|}
\hline & $\mathrm{a}(\mathrm{kPa})$ & $\mathrm{n}$ & $\mathrm{m}$ & $\mathrm{R}^{2}(\%)$ & $\mathrm{SSE}$ \\
\hline Volcanic sand & 1.87 & 9.14 & 0.68 & 99.96 & $1.6 \mathrm{e}-3$ \\
\hline Glass beads & 3.03 & 28.73 & 0.82 & 99.65 & $1.15 \mathrm{e}-2$ \\
\hline Fine sand & 4.23 & 8.25 & 0.85 & 99.82 & $5.60 \mathrm{e}-3$ \\
\hline Touch silt loam & 8.68 & 6.49 & 0.75 & 99.97 & $1.26 \mathrm{e}-3$ \\
\hline
\end{tabular}

Table 2: Computed SWCC variables for four types of soil

\begin{tabular}{|c|c|c|c|}
\hline & AEV (kPa) & $\begin{array}{c}\text { Residual } \\
\text { suction }(\mathrm{kPa})\end{array}$ & $\begin{array}{c}\text { Residual } \\
\text { saturation }\end{array}$ \\
\hline Volcanic sand & 1.64 & 3.34 & 0.12 \\
\hline Glass beads & 2.00 & 4.37 & 0.02 \\
\hline Fine sand & 3.51 & 8.11 & 0.07 \\
\hline $\begin{array}{c}\text { Touch silt } \\
\text { loam }\end{array}$ & 7.23 & 17.93 & 0.12 \\
\hline
\end{tabular}

Table 2 indicates that SWCC variables can be calculated from the SWCC fitting parameters using Zhai and Rahardjo's (2012) equations. Figure. 5 indicates that prediction results from Zhai and Rahardjo's (2015) equation agree very well with the experimental results. In other words, the permeability function can also be calculated directly from the fitting parameters.

The confidence limits of SWCC for the four types of soil as computed using Zhai and Rahardjo's (2013b) equations are illustrated in Figure. 6. On the other hand, the permeability function for these four types of soil as computed from the best fitted SWCC and the confidence 
of limits of the SWCC using Zhai and Rahardjo's (2015) equation are illustrated in Figure. 7.

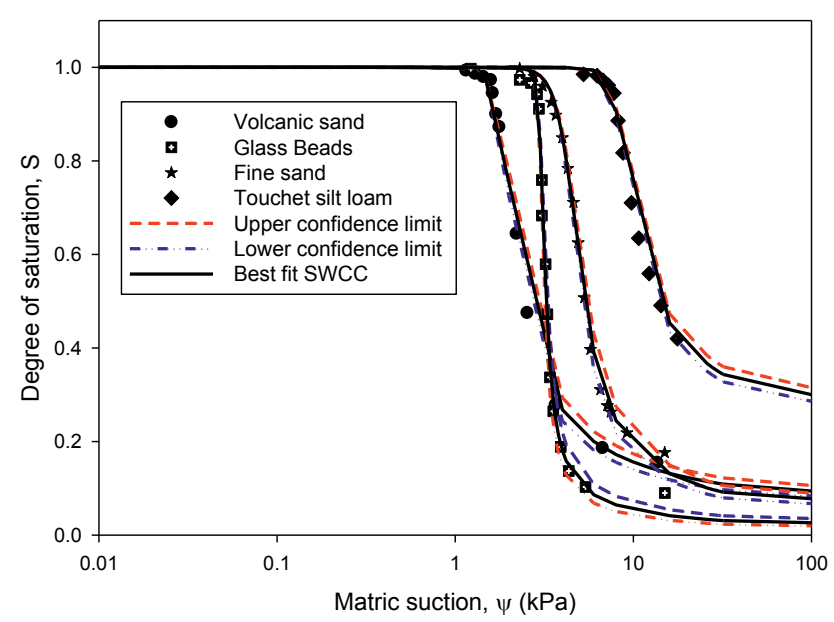

Figure. 6 Confidence limits of SWCC for four types of soil using Zhai and Rahardjo's (2013b) equations

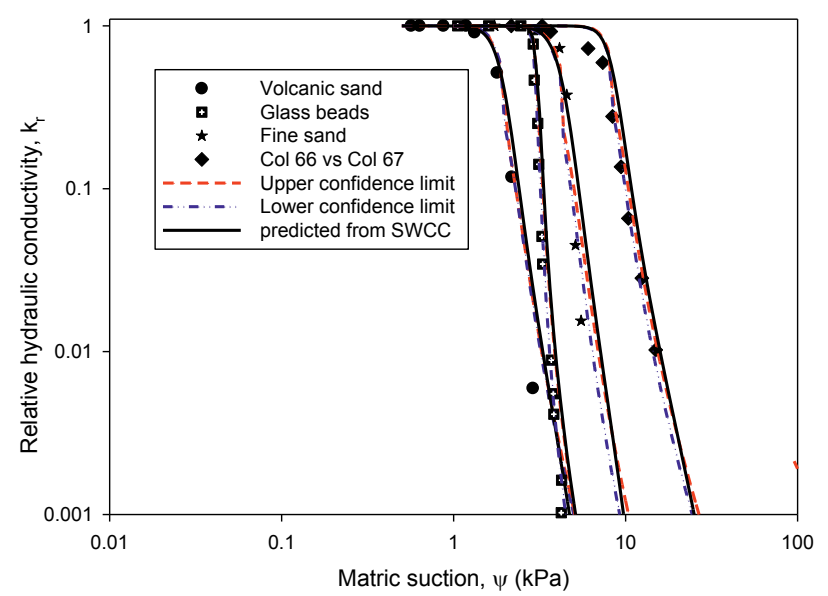

Figure. 7 Confidence limits of permeability function for four types of soil using Zhai and Rahardjo's (2015) equation

Figure. 6 indicates that uncertainty in SWCC can also be estimated from the fitting parameters and the residual error using Zhai and Rahardjo's (2013b) equations. Figure. 7 indicates that variation in permeability function can also be estimated from the confidence limits of SWCC.

\section{Conclusions}

The SWCC variables such as air-entry value, residual suction and residual saturation can be computed from the SWCC fitting parameters using Zhai and Rahardjo's (2012) equations. The permeability function can be predicted from the SWCC fitting parameters using Zhai and Rahardjo's (2015) equation. On the other hand, the uncertainty in the SWCC can also be estimated from the fitting parameters and the residual error using Zhai and Rahardjo's (2013b) equations. Subsequently, the variation in permeability function can also be estimated from the confidence limits of SWCC. In other words, the equations proposed by Zhai and Rahardjo (2012a, 2012b, 2013, and 2015) provide a convenient method to estimate the SWCC variables, permeability function and their variations using an electronic spreadsheet.

\section{References}

1. Brooks, R.H., and Corey, A.T. "Hydraulic properties of porous media."Hydrology Paper, No. 3 Colorado State Univ., Fort Collins Colo. (1964)

2. Farrel. D.A. and Larson W.E. "Modeling the pore structure of porous medium. "Water Resour. Res. 3 699-706 (1972)

3. Fredlund, D.G. and Xing, A. "Equations for the soilwater characteristic curve." Canadian Geotechnical Journal, 31(3): 521-532. (1994)

4. Gardner, W.R "Mathematics of isothermal water conduction in unsaturated soils."Highway Research Board Special Rep. No. 40, International Symposium on physic-Chemical Phenomen in Soils, Washigton, D.C. 78-87. (1958)

5. Kosugi K "Three-parameter lognormal distribution model for soil water retention". Water Resources Research Vol 30 No. 4 Pages 891-901. (1994)

6. Leong, E.C. and Rahardjo H. "Review of soil-water characteristic curve equations." J. Geotech. Geoeniron. Eng 123(12), 1106-1117. (1997)

7. Satyanaga, A., H. Rahardjo, E.C. Leong and J.Y. Wang. "Water Characteristic Curve of Soil with Bimodal Grain-size Distribution".Computer and Geotechnics, January, Vol. 48, pp. 51-61. (2013)

8. Sheng, D., Fredlund, D.G., and Gens, A. " A new modeling approach for unsaturated soils using independent stress state variable" ". Canadian Geotechnical Journal, Vol. 45, pp. 511-534. (2008)

9. van Genuchten, M.T. "A close form equation predicting the hydraulic conductivity of unsaturated soil.” Soil Sci. Soc Am. J 44, 892-898. (1980)

10. Vanapalli, S. K., Fredlund, D. G., Pufahl, D. E. and Clifton, A. W. "Model for the prediction of shear strength with respect to soil suction", Canadian Geotechnical Journal, Vol. 33, pp. 379-392. (1996)

11. William. J., Prebble.R.E., Williams W.T. and Hignett, C.T. "The influence of texture, structure and clay mineralogy on the soil moisture characteristics." Australian J. of Soil Res. 21, 15-32 (1983)

12. Zapata, C. E. "Uncertainty in Soil-Water Characteristic Curve and Impacts on Unsaturated Shear Strength Predictions", Ph.D. Dissertation, Arizona State University, Tempe, United States. (1999)

13. Zhai Q, Rahardjo H. "Determination of soil-water characteristic curve variables." Comput Geotech 2012;42:37-43. (2012a)

14. Zhai Q, Rahardjo H. " Reply to the discussion by Bellia et al. on "Determination of soil-water characteristic curve variables"by Zhai Q, Rahardjo H. Comput Geotech 2012;42:37-43 " Comput Geotech Volume 45, Pages 151-152 (2012b)

15. Zhai Q, Rahardjo H. "Soil-Water Characteristic Curve Variables." Conference paper, Proceeding of 
the International Symposium on Unsaturated Soil Mechanics and Deep Geological Waste Disposal, Shanghai, China, 07-10 July (2013a)

16. Zhai Q, Rahardjo H. "Quantification of uncertainty in soil-water characteristic curve associated with fitting parameters" Engineering Geology 163 144$152(2013 b)$
17. Zhai Q., and Rahardjo H. "Estimation of permeability function from Soil-Water Characteristic Curve”. Engineering Geology 199 :148-156 (2015) 